This is an Accepted Manuscript of an article published by Taylor \& Francis in Biofuels on 7 Apr 2015, available online: http://www.tandfonline.com, DOI: 10.1080/17597269.2015.1024387.

Full Citation:

Musgrove, E. and S. Heaven, Investigating the hydrodynamic performance of carbonation sumps in High Rate Algal Pond (HRAP) raceways using computational fluid dynamics (CFD). Biofuels, 2015: p. 1-17.

\title{
Investigating the hydrodynamic performance of carbonation sumps in High Rate Algal Pond (HRAP) raceways using computational fluid dynamics (CFD)
}

\author{
Authors \\ Edward Musgrove ${ }^{* 1} \&$ Sonia Heaven ${ }^{1}$ \\ Faculty of Engineering and the Environment, University of Southampton, University Rd, \\ Southampton SO17 1BJ \\ * Author for correspondence \\ Tel.: ++44 2380525386 \\ e.musgrove@soton.ac.uk
}

\section{Financial \& competing interests disclosure}

This work was supported by the EU FP7 All-Gas Project under grant number 268208 and by a scholarship from the UK's Engineering and Physical Sciences Research Council, EP/K503150/1.

\begin{abstract}
The production of microalgae requires carbonation and deoxygenation which is commonly supplied through a sump. This needs to be designed to minimise the energy loss to ensure a high net energy gain from the biofuel. Computational fluid dynamics was used to evaluate different sump designs and flow velocities in terms of energy loss and flow distribution to find the optimum configuration. It was established that increasing the radius of curvature of the corners to $0.1 \mathrm{~m}$ and the implantation of one flow deflector resulted in a reduction in hydraulic power of $73 \%$ compared to the basic setup. It was apparent that the central baffle resulted in considerable energy loss and when this was removed than a power saving of $95 \%$ was possible. There was, however, a much reduced flow around the sump leading to shortened contact time between the gas and fluid which could in turn decrease the carbonation of the fluid. It was also apparent that the use of standard formulas for the calculation of head loss was not applicable.
\end{abstract}

\section{Key words}

Carbonation Sumps, Computational Fluid Dynamics (CFD), High Rate Algal Ponds (HRAP), Deoxygenation, Hydraulic power, Head loss 


\section{Defined key words}

Computational Fluid Dynamics (CFD): The use of numerical methods and algorithms to resolve and visually present problems arising in fluid flows.

Reynolds number: The ratio of inertia forces to viscous forces used to estimate flow formations.

Volume of fluid model: A numerical method for modelling two or more fluids with different characteristics.

k-epsilon: A two-equation turbulence model based on the turbulent kinetic energy ( $k$ ) and the dissipation (epsilon).

Boundary conditions: A set of assumptions defining the extremities of the model.

Turbulence intensity: A scale value defining the amount of turbulence in a fluid. A laminar fluid flow with no variations would have a value of $0 \%$.

Convergence criteria: A set of residual values that must be reached to ensure that the simulation has become steady.

\section{$1 \quad$ Introduction}

Microalgae have recently been seen as a possible source of biomass for biofuel production [1]. Raceway systems have been described as the most feasible reactor type for large-scale cultivation for this purpose [2,3]. The typical raceway configuration dates back to Oswald and Golueke [4], and consists of an extended channel with a central dividing wall and a paddlewheel to drive the cultivation medium around the system. The raceway depth is normally 0.2-0.3 m [5-7], but can be up to $0.5 \mathrm{~m} \mathrm{[8]}$. Depths greater than this lead to the algae spending extended periods of time in darkness; reducing biomass productivity [6]. Currently, the surface area of individual raceways is most commonly $3000 \mathrm{~m}^{2}$, but can reach $5000 \mathrm{~m}^{2}[9,10]$. The large surface area to depth ratio ensures maximum light penetration into the culture.

Forward velocities in the range of $0.15-0.3 \mathrm{~m} \mathrm{~s}^{-1}$ are most common due to the need to maintain the algae in suspension while keeping pumping costs low [11]. The minimum fluid velocity to keep the algae in suspension is generally quoted as $0.1 \mathrm{~m} \mathrm{~s}^{-1}$; if the velocity drops below this critical value sedimentation of algae may occur [12,13]. Areas of sedimentation will also lead to a shorter residence time because of the reduced effective volume. These areas of deposition are called dead zones and are normally characterised as areas of recirculating flow.

Shear stress in fluids occurs in turbulent flows as the water particles are not travelling with a uniform velocity but have a relative velocity to one another. This stress can enhance algal growth until an optimal value is reached whereupon there is a decrease in the biomass concentration due to damage caused to the algae. The optimal value of shear stress depends entirely upon the microalgae selected $[14,15]$. Thomas and Gibson, 1990, proposed a scale of inhibition due to this stress where: green algae < blue-green algae < diatoms $<$ dinoflagellates [16].

Algae can assimilate $\mathrm{CO}_{2}$ from the atmosphere but biomass yields can be increased if the medium is supplemented with addition $\mathrm{CO}_{2}$ [17-19]. In a study where $\mathrm{CO}_{2}$ was injected into a carbonation sump, it was found that $66 \%$ of carbon supplied was taken up by biomass [20]. Enriching the $\mathrm{CO}_{2}$ in the air used for sparging the culture has been shown to increase biomass yields $[21,22]$. These 
investigations indicate that the algae are in fact carbon limited if no carbon source is added to the system $[23,24]$. This can be explained by the fact that for every $1 \mathrm{~kg}$ of algae biomass grown in the reactor $1.65-2.2 \mathrm{~kg}$ of carbon dioxide will be needed $[25,26]$. As the carbon availability decreases the alkalinity in the culture rises [11]. At values above $\mathrm{pH} 10$ this will be adverse for algal growth $[5,27,28]$. As a result of photosynthesis, oxygen builds up in the system and when concentrations reach $200-300 \%$ of saturation algal growth will be inhibited $[5,29,30]$.

One simple solution to these problems is to bubble $\mathrm{CO}_{2}$ gas into the culture medium thus increasing the gas transfer of $\mathrm{CO}_{2}$ into the system and $\mathrm{O}_{2}$ out of it [20,31,32]. Weissman et al. [33], reported that a $80-90 \%$ gas transfer was achieved using a $0.91 \mathrm{~m}$ deep sump, and that increasing the depth further had little impact on the $\mathrm{CO}_{2}$ transfer. It did, however, account for a large proportion, $17-25 \%$, of the total energy requirement for circulating the cultivation medium around the raceway. The sump depth dramatically affects the energy required in the system. Reducing the depth of a $3 \mathrm{~m}$ sump by $50 \%$ can lead to a decrease of over $50 \%$ in the energy used [2].

Computational Fluid Dynamics (CFD) has been used to investigate a number of different elements of raceway design: the raceway bends [9] and complete raceways without a sump [6,34,35]. Although these CFD investigations have primarily used the same methods they have obtained vastly different results, varying by an order of magnitude. This can be attributed to the lack of validation of these models due to the paucity of empirical data from large-scale plants.

More recently the modelling of raceways has become more sophisticated with the use of free surface models [36,37]. Some studies have even modelled the motion of the paddlewheel within the mesh [38]. These models have been validated against small scale experiment data and give a much more reliable insight into the hydrodynamic characteristics of the raceway. They have not, however, investigated different geometrical parameters of the raceway. Other CFD studies have investigated the hydrodynamic behaviour of open channel $90^{\circ}$ bends with and without flow deflectors, although not directly in the context of raceway design [39-42]. There has, however, been little experimental or computational modelling of the fluid flow in sumps.

This paper evaluates a range of sump designs with the aim of identifying means of reducing the head loss, percentage area of dead zones and calculating the shear stress in carbonation sumps. This has been done with the use of CFD, but unlike some other CFD investigations a multiphase volume of fluid model has been used in order to simulate accurately the effects of open channel flow.

\section{$2 \quad$ Methodology}

\section{$2.1 \quad$ Flow simulations}

All of the sump designs were modelled using Ansys CFX code which utilises finite element analysis to simulate the flow. Simulations were carried out using two-dimensional (2-D) flow conditions, as the edge effects in a full-scale system are assumed to be negligible and the increase in computational memory needed to run three dimensional simulations made this unfeasible. Using a 2-D model also means the results can easily be transferred to carbonation sumps of other sizes. All of the simulations were set up as steady state analyses due to the focus on the hydrodynamic performance of the sumps.

A homogeneous volume of fluid (VOF) model was employed so that the interface between water and air could be properly modelled, with no artificial surface constraints applied to the simulation. This allowed the depth of the water to rise to a realistic level due to the backwater effect from the 
sump. The standard free surface model was applied to ensure that excessive diffusion between the two different fluids did not occur.

The turbulence was modelled using Reynolds averaged Navier-Stokes (RANS) equations. The standard k-epsilon turbulence model was implemented in the simulation. The turbulent kinetic energy $(k)$ and dissipation rate $(\varepsilon)$ is given by:

$$
\begin{aligned}
& \frac{\partial \rho k}{\partial t}+\frac{\partial \rho U_{j} k}{\partial x_{j}}=\frac{\partial}{\partial x_{j}}\left[\left(\mu+\frac{\mu_{t}}{\sigma_{k}}\right) \frac{\partial k}{\partial x_{j}}\right]+P_{k}-\rho \varepsilon+P_{k b} \\
& \frac{\partial \rho \varepsilon}{\partial t}+\frac{\partial \rho U_{j} \varepsilon}{\partial x_{j}}=\frac{\partial}{\partial x_{j}}\left[\left(\mu+\frac{\mu_{t}}{\sigma_{\varepsilon}}\right) \frac{\partial \varepsilon}{\partial x_{j}}\right]+\frac{\varepsilon}{k}\left(C_{\varepsilon 1} P_{k}-C_{\varepsilon 2} \rho \varepsilon+C_{\varepsilon 1} P_{\varepsilon b}\right)
\end{aligned}
$$

where $P_{k}$ represents the turbulence generation due to viscous forces and $P_{k b}$ and $P_{\varepsilon b}$ denotes the generation of turbulence kinetic energy from buoyancy forces. The model makes the assumption that the turbulence viscosity $\left(\mu_{t}\right)$ is related to the kinetic energy and dissipation rate:

$\mu_{t}=\frac{C_{\mu} \rho k^{2}}{\varepsilon}$

In the model $\sigma_{k}$ and $\sigma_{\varepsilon}$ are the Prandtl numbers for kinetic energy and dissipation rate. $C_{\varepsilon 1}, C_{\varepsilon 2}$ and $C_{\mu}$ are turbulence model constants. In this simulation the standard values for these constants where applied: $\sigma_{k}=1.0, \sigma_{\varepsilon}=1.3, C_{\varepsilon 1}=1.44, C_{\varepsilon 2}=1.92$ and $C_{\mu}=0.09$ [43].

The k-epsilon turbulence model is the most widely validated turbulence model when the simulation is free from large pressure gradients. This turbulence model has been extensively analysed and compared to experimental data for flows around bends in open channels $[39,41]$ and has also been applied in other raceway simulations investigating bend geometries $[9,34]$.

Convergence criteria were set at a mass, momentum and turbulent kinetic energy residual of both fluids of at least $1 \times 10^{-4}$ with a mass and momentum imbalance conservation target of $1 \times 10^{-3}$. When the residual target was met oscillations occurred due to instabilities in the model caused by the multiphase flow and surface entrainment of air into the water. At larger radii of curvature the model became progressively more unstable due to the greater changes in the flow cross-sectional area. This had a greater effect on the results for the higher velocities as there was greater instability between the two phases.

The mesh for all the different geometries was hexahedral with a minimum length of $0.01 \mathrm{~m}$. Mesh adaptation was set to refine the mesh along the free surface. This was to ensure accurate modelling at the area of instability and thus increase the convergence of the solution.

\subsection{Boundary conditions}

The boundary conditions for the bottom of the reactor and the baffle were considered to be a nonslip smooth wall to simulate the fibreglass used in the reactor construction. As the simulation was a two-dimensional model the sides were set as a symmetry boundary, meaning that the fluid on either side of the boundary behaves in the same. As a result of this boundary setting there was no lateral flow across the reactor. This was considered acceptable as lateral flows are not considered to be imperative in the system. The upper surface of the model was set up as an open boundary allowing free movement of air in and out of the system so that no artificial pressures were applied to the free surface. 
The initial location of the free surface was established by setting the fraction of volume of the different fluids flowing into and out of the system, which was executed using the CFX Expression Language (CEL) functions. The inflow boundary was set up as a velocity inlet $5 \mathrm{~m}$ upstream of the centre line of the sump. The outlet was set up as a static pressure outlet with a relative pressure correlating to a depth of $0.15 \mathrm{~m}$, located $15 \mathrm{~m}$ downstream of the sump centre line (Figure 1). This therefore acted as a downstream weir condition influencing the open surface water height for the whole system. This ensured that conditions at the outlet of the model did not interfere with the calculated head loss across the sump.

For the first set of investigations into the curvature of the corners different velocities were tested. For the other investigations a velocity of $0.27 \mathrm{~m} \mathrm{~s}^{-1}$ was used. If the inlet turbulence intensity $(I)$ is assumed to be fully developed its value can be calculated [44]:

$I=0.16 R e^{-\frac{1}{8}}$

(Equation 4)

where $R e$ is the Reynolds number. The intensity was calculated to be $3.5-4 \%$ for the range of inlet velocities tested; this was similar to the value found in other CFD investigations into raceways [36]. As the use of this formula is an approximation and the intensity at the inlet is unknown and dependent upon the upstream history of the flow an intensity of $5 \%$ was chosen as the recommended value [43].

\subsection{Hydraulic power requirement calculation}

Determination of the power required to pump the water across the sump requires calculation of the head loss. The total head loss is the sum of the minor and major head loss. The major head loss, arising from friction with the channel, is negligible due to the short length of channel being considered. The minor head loss $\left(h_{L}\right)$ across the obstacle can be calculated:

$h_{L}=K \frac{v_{2}^{2}}{2 g}$

(Equation 5)

where $K$ is the minor head loss coefficient, $v$ is the velocity $\left(\mathrm{m} \mathrm{s}^{-1}\right)$ and $g$ the acceleration due to gravity $\left(\mathrm{m} \mathrm{s}^{-2}\right)$. Due to the non-standard bend configuration, however, the minor head loss coefficient is not known. Thus to calculate the head loss Bernoulli's Equation can be rearranged:

$h_{L}=\alpha \frac{v_{1}{ }^{2}}{2 g}+z_{1}-\left(\alpha \frac{v_{2}{ }^{2}}{2 g}+z_{2}\right)$

(Equation 6)

where $\alpha$ is the kinetic energy correction coefficient and $z$ is the depth $(m)$. In turbulent flows the kinetic energy correction coefficient is generally considered to be close to one. When it was used in calculation of the head loss it was found to result in a less than $1 \%$ difference and was therefore neglected.

The velocity and depth values used for the calculation of energy losses were taken at two points $4 \mathrm{~m}$ upstream (location 1) and downstream (location 2) of the sump centreline (Figure 1). This was to ensure that the inlet and outlet boundary condition had little effect on the flow on the fluid to represent a continuous raceway.

The hydraulic power required is related to the volume of fluid in the sump: the larger it is, the more power is needed [2]. It is therefore necessary to calculate the power per unit of volume to allow comparisons to be made between sumps: this approach has been adopted for other computational and experimental studies into raceways $[7,35]$. The results of this work cannot be directly compared to those studies, however, as in this investigation only the volume $4 \mathrm{~m}$ upstream and downstream of 
the sump is considered and therefore the power requirement per unit volume is much higher than in the whole raceway. The head loss from Equation 6 can be used to calculate the hydraulic power requirement per unit cross-sectional area per unit width of the sump as follows:

$P=\frac{\rho g Q h_{L}}{A_{\text {Sump }} W}$

(Equation 7)

where $P$ is the hydraulic power required per unit of cross-sectional area per unit width $\left(\mathrm{W} \mathrm{m}^{-2} \mathrm{~m}^{-1}\right), \rho$ is the density of water $\left(\mathrm{kg} \mathrm{m}^{-2}\right), Q$ is the discharge $\left(\mathrm{m}^{3} \mathrm{~s}^{-1}\right), A_{\text {Sump }}$ is area of the sump $\left(\mathrm{m}^{2}\right)$, and $W$ is the unit width $(\mathrm{m})$

\subsection{Dead zone calculation}

Dead zones can be defined as volumes of water with a flow velocity of less than $0.1 \mathrm{~m} \mathrm{~s}^{-1}$ which thus become stagnant due to limited mixing with the main flow. It is important to minimise these areas in the sump as they reduce the effective volume in which gas exchange can occur. The percentage area can be calculated as:

Dead Zone Percentage $=\frac{V_{v<0.1}}{V_{\text {total }}} \times 100$

(Equation 8)

where $V_{v<0.1}$ is the volume of water with a velocity less than $0.1 \mathrm{~m} \mathrm{~s}^{-1}$ and $V_{\text {total }}$ is the total volume of the water in the sump.

\subsection{Shear stress calculation}

Shear stresses in moving fluids arise as a result of the non-uniform flow and that the fluid particles have a relative velocity to one another. Shear stresses in fluids arise mainly within the boundary layer due to the resistance to the flow from the sides of the reactor. As at the point of contact between the fluid and the solid wall the velocity is zero and at some height above the wall the fluid velocity is similar to that of the main flow.

The shear stress $(\tau)$ arising in the fluid can be calculated using Newton's law of viscosity:

$\tau=\mu \frac{\partial u}{\partial y}$

(Equation 9)

where $\mu$ is the dynamic viscosity $\left(\mathrm{N} \mathrm{s} \mathrm{m}^{-2}\right)$ and $\frac{\partial u}{\partial y}$ is the velocity gradient or the rate of shear strain $\left(\mathrm{s}^{-}\right.$ $\left.{ }^{1}\right)$.

\subsection{Sump designs}

The basic configuration used in modelling was based on designs reported in the literature $[7,33]$. The simulated sump is $0.6 \mathrm{~m}$ long $\times 1 \mathrm{~m}$ deep and was assumed to be constructed from fibreglass. The different sump designs tested can be split into four distinct groups. Increasing the radius of curvature of bends has been shown to decrease the head loss in open channels [45]. The first set of simulations thus investigated the effect of increasing the radius of curvature of the corners in the sump, using $0.01,0.1,0.15$ and $0.3 \mathrm{~m}$ radii (Figure $2 \mathrm{a}$ ).

Central island configurations have been shown to reduce head loss and dead zones in the horizontal end bends in raceways $[9,34,35]$. The second group of design modifications therefore attempted to apply a similar concept in a vertical plane within the sump by examining how increasing the sump barrier thickness affected the flow. These simulations were done using the geometry of the basic, 
$0.1 \mathrm{~m}$ and $0.3 \mathrm{~m}$ curvature sumps with a flow of $0.055 \mathrm{~m}^{3} \mathrm{~s}^{-1}$. The barrier thicknesses tested were $0.02,0.05,0.1,0.2$ and $0.3 \mathrm{~m}$ wide (Figure $2 \mathrm{~b}$ ).

Flow deflectors have been shown to minimise the head loss and the proportion of dead zones in the $180^{\circ}$ horizontal bends in raceway reactors [7,9,34]; however this idea of vaned flow reducing the power requirement has been disputed in other CFD investigations [35]. Deflectors have been shown to reduce secondary flows and separation zones in $90^{\circ}$ bends, resulting in a lower head loss [40], although again this was for bends in the horizontal plane only. Hence vertical flow deflectors in the bottom section of the sump were investigated (Figure 2c); again this was done for the basic, 0.1 and $0.3 \mathrm{~m}$ designs at a flow of $0.055 \mathrm{~m}^{3} \mathrm{~s}^{-1}$.

The final set of investigations was into the baffle length and how reducing this would affect the circulation flow in the sump and the power requirement (Figure 2d). Removing the baffle has been shown to reduce the power requirement substantially in some situations [7], but the effect of a small gap between the top of the baffle and the water surface on both the power requirement and the circulation around the sump has not previously been investigated.

\section{$3 \quad$ Model validation}

To validate the numerical model the velocity and depth values at location 1 and 2 (Figure 1) were collected from the raceway rector located at the Estacion Experimental Las Palmerillas of Fundacion CAJAMAR in Almeria, Spain. The sump used in this raceway is $0.65 \mathrm{~m}$ long $\times 1 \mathrm{~m}$ deep and located partway down one of the $50 \mathrm{~m}$ long straight sections [7]. These experimental values are used to calculate the hydraulic power requirement to pump the water across the sump. A sump with the same geometry to this was simulated using the boundary and initial conditions as described previously. The numerical and experimental results were compared (Figure 3a). The numerical results showed good agreement with the experimental results across the entire range of discharges.

For further validation, experimental data from the work on the design and operation of an outdoor microalgal test facility for the US Department of Energy's Aquatic Species Program has been compared to simulated results. During this work researchers measured the head loss on a $0.91 \mathrm{~m}$ deep $\times 0.62 \mathrm{~m}$ wide sump with $6.5 \mathrm{~cm}$ radius in all corners [33]. Again a sump with the same geometry has been simulated in the model. The variations in the power requirement with discharge showed good a good relationship between numerical and experimental results (Figure $3 \mathrm{~b}$ ). The simulated results are greater than the experimental results by $5-10 \%$ at the higher discharges. The discrepancies between the two data sets were larger at the lower discharges tested; this may be linked to reported problems in collecting the experimental data at the slower fluid velocities $[12,33]$.

\section{$4 \quad$ Results and discussion}

\subsection{Depth}

For all geometries tested it was found that as the inlet velocity was increased the depth of water rose (Figure 4). This is due to the backwater effect caused by an obstacle, the sump, obstructing the flow. The greater the fluid velocity the more water will 'back up', as there is a greater discharge trying to pass through the obstacle in a given time.

Rounding of the corners of the sump did cause significant changes in the depth of the fluid, especially at a radius of $0.1 \mathrm{~m}$. This is as a result of the fluid being able to flow more freely through the structure causing a minimal backwater curve. At the greater radii of curvature the water depth is 
greater as the flow through the sump becomes less efficient and the backwater effect is more noticeable.

\subsection{Hydraulic power}

The power requirement depends on the flow area and velocity. Due to the change in upstream depth and therefore in flow area, the discharge must be used when comparing the power consumption for the various simulated geometries (Figure 5).

For the basic and rounded geometries tested there was a cubic increase in power as discharge increased. This is validated by the concept that the hydraulic power requirement is linked to the velocity head and has also been the case in other CFD investigations into power requirement for raceways [35]. The rise in power occurs due to the fact that there are greater frictional and turbulence losses in the system at higher velocities. Flow separation accounts for a large proportion of the energy loss in flows around bends $[39,40]$, and this occurred more frequently and to a greater extent at the higher inlet velocities tested. Increases in the flow separation at the higher velocities have been confirmed by other experimental studies into open channel flow [46].

The power requirement was also affected by the radius of curvature of the sump corners. When the corners were rounded to a radius of curvature of $0.01 \mathrm{~m}$ there was an average power saving of $10 \%$ in the range tested based on the applied trend lines (Figure 5). Increasing this radius further to $0.1 \mathrm{~m}$ reduced the power consumption by $40 \%$ compared to the basic configuration. Similar effects have been shown in investigations into $90^{\circ}$ bends in open channels [29]. Rounding the corners means that the change in the flow direction is less abrupt, resulting in the reduction or elimination of the flow separation zones located after the corners (Figure 6). Flow separation did not occur at all on the entry and exit corners for the $0.1 \mathrm{~m}$ curvature sump even at the greatest velocity tested (Figure $6 \mathrm{~d}$ ). This elimination of the separation zone is the main reason for the large reduction in power requirement.

The two most rounded sump configurations, with $0.15 \mathrm{~m}$ and $0.3 \mathrm{~m}$ curvatures, were less efficient than less rounded ones. This is due to the greater flow expansion angle at the entrance corners of these configurations leading to higher turbulent losses due to the greater rate of change in cross sectional area. This increase in energy loss with increased expansion angle is supported by empirical data [47].

Increasing the sump barrier width initially reduced the power requirement by up to $30 \%$ for the basic and $0.3 \mathrm{~m}$ radius sump geometries (Figure 7 ). This can be attributed to the fact that there was a reduction in flow separation after the baffle, and more uniform flow through the sump. The more uniform flow results in less intense localised velocity spikes (Figure 8 ) and thus reduces the resulting energy loss. Increasing the internal radii of the central baffle has also been shown to reduce the power requirements for $180^{\circ}$ horizontal bend simulations $[9,34,35]$ and also for $90^{\circ}$ horizontal bends [45].

After the critical width of the barrier, i.e. the point of lowest energy loss, was passed there was a steady rise in the power required. This can be attributed to a flow constriction being applied as the width of the channel was reduced (Figure 8d). As a result of the flow constriction there was an increase in the velocity within the sump to ensure continuity was maintained, which resulted in more energy dispersion.

Flow deflectors in horizontal channels have been shown to reduce the power requirement both theoretically and experimentally $[7,40]$. This was also the case in this investigation; when one flow deflector was implanted in the basic and $0.1 \mathrm{~m}$ radius sumo geometries a reduction of over $50 \%$ was 
observed (Figure 9). This is caused by an increase in the uniformity of the fluid velocity across the flow area (Figure 10a, b). The more uniform flow resulted in a reduced maximum velocity in the sump and therefore less turbulence. The implementation of deflectors resulted in a reduction in the separation zones behind the baffle and after the entry corner. This reduction of separation zones will again result in less dissipation of energy through turbulence, as has been shown for $90^{\circ}$ open channel bends with deflectors [40].

The implementation of multiple deflectors had varying effects depending upon the geometry of the sump and also the number. The general increase in power requirement can be attributed to the fact that there were greater frictional losses in the system due to the increased wall. With a single deflector, this increase in frictional loss was balanced by the increase in flow efficiency; however there was no further net improvement when extra deflectors were implemented. This result has also been seen with the use of deflectors in the $180^{\circ}$ bends at the end of raceways [9].

The power requirement decreased substantially as the length of the barrier was reduced (Figure 11). This is due to the fact that less flow was being forced around the sump by the baffle and that the main area of flow was able to pass through relatively unhindered. Small areas of flow separation occurred on the downstream side of the top of the baffle which resulted in higher energy losses. These were negated, however, by the energy savings from fluid not being forced around the length of the sump.

When the baffle length was reduced so that there was no obstruction to the main flow a minimum power requirement of $1.5 \mathrm{~W} \mathrm{~m}^{-2} \mathrm{~m}^{-1}$ was reached. There was, however, very little flow through the sump (Figure 12). While in practice the introduction of gas at the base of the sump will ensure some mixing between the gas and liquid however this reduced flow means the contact time may be reduced, potentially resulting in insufficient gas transfer.

These theoretical results are similar to those seen in the experimental work done by Mendoza et al. [7], who reported that the inclusion of the baffle resulted in a dramatic rise in the power requirement; but they provide an additional insight into the mechanisms and thus potentially to possible options for amelioration or exploitation.

\subsection{Dead zones}

The area occupied by dead zones reduced as the velocity increased, as more energy was present in the system. Complete removal of the dead zones through increased velocity alone is not feasible as the power requirement will be too great. Changing the shape of the sump does not greatly influence the percentage of these zones as the flow expansion in the sump leads to velocities of less than 0.1 $\mathrm{m} \mathrm{s}^{-1}$ in some areas (Figure 6). Unexpectedly, the radius of curvature giving the highest reduction in the dead zone area was $0.01 \mathrm{~m}$. This can be attributed to the fact that the flow separation forces the flow into the inner parts of the sump, but as a result of the slight rounding the length of the separation zone is reduced.

Increasing the width of the sump barrier drastically reduced the area of dead zones, by $53-67 \%$ at the maximum barrier widths simulated. This major reduction is a result of these dead zone areas effectively being filled in by the barrier. Similar behaviour has been shown in studies investigating the horizontal $180^{\circ}$ bends at the end of raceways [9]. The advantages of this configuration are limited, however, as the total area is also reduced and so the total volume where effective gas exchange can occur does not increase.

The use of flow deflectors reduced the area of dead zones by up to $25 \%$ and $39 \%$ for basic and the $0.1 \mathrm{~m}$ radius configurations. This is because the flow through the sump was more uniform as the 
water is directed through the vaned passages, and as a result the flow separation length was reduced. This effect was far less than that seen in a study on horizontal raceway channel sections which found that the incorporation of deflectors led to a 14-fold reduction of the dead zone area [9], which could be an effect of the difference in scale between the two models.

For the fully rounded sump, vaned flow has a strong negative impact on the area occupied by dead zones as the flow is forced towards the outer sections of the bend, thus decreasing the velocity in the inner areas (Figure 10c). This led to a $38-50 \%$ rise in the dead zone area when any number of deflectors were introduced.

The dead zone area increased substantially as a gap was introduced at the top of the barrier (Figure 12). This is mainly due to the lack of circulating flow around the barrier and into the sump. When the top of the barrier was at the same depth as the bottom of the channel there was a small amount of circulation flow due to flow separation caused by the barrier. When the top of the barrier was reduced further to below the main channel of flow there was no flow into the sump resulting in a completely stagnant area.

\subsection{Shear strain}

The calculated shear stress for each sump geometry increased linearly with rising fluid velocity (Figure 13a). This resulted from the dynamic viscosity and boundary layer thickness remaining constant and the only changing variable was the velocity.

The localised velocity increases affect the shear stress applied to the moving fluid dramatically. In these areas there was a much larger relative velocity between the moving and stationary fluid particles resulting in greater shear stresses. As the radius of curvature is enlarged to $0.01 \mathrm{~m}$ there was more uniform flow throughout the sump channels (Figure 6), which lead to a $30 \%$ reduction in the shear stress in the fluid. Enlarging the radius of curvature from $0.01 \mathrm{~m}$ to $0.1 \mathrm{~m}$ has less of an affect and there was no significant change in the shear stress when the radius of curvature passes $0.1 \mathrm{~m}$. This is due to there being less change in the uniformity of the fluid velocity profile.

Small increases in the sump barrier width reduced the shear stress across all of the different configurations tested (Figure 13b). For all geometries the minimum shear stress occurred at around a barrier width of $0.05 \mathrm{~m}$ to $0.1 \mathrm{~m}$. This can be again attributed to a more uniform flow and less intense velocities occurring after the sump barrier (Figure 8 ). This has also been experienced by other investigations into the complete raceways $[35,48]$. Similarly to the hydraulic power results after these widths were passed the shear stress than began to rise. This is caused by the constriction of the fluid in the sump channels leading to rising velocity.

The introduction of flow deflectors in the sump had similar effects across all the different geometries tested (Figure 13c). The use of one deflector reduces the shear stress by $27 \%$ for the basic configuration. Once more this is credited to the reduction in the variation in the velocity profile. Using more than one deflector, however, starts to increase the shear stress as there is a larger surface area of boundary wall in contact with the fluid. Similar results have been found for the complete raceways when three deflectors were introduced there was a $20 \%$ rise in the shear stress [35]. The fully rounded geometry has a greater rise in the shear stress than that of the $0.1 \mathrm{~m}$ radius and basic geometries as more deflectors are introduced. This is a result of the much higher flow velocities experienced by the fluid at the bottom of the sump (Figure 10c).

\subsection{Head loss}

The head loss data for the basic geometry can be used to calculate a minor loss coefficient for this sump using Equation 5. According to this equation there should be a linear correlation between the 
velocity head and the head loss; the correlation was not linear, however, but quadratic. It can therefore be concluded that there must be an additional factor involved in the minor head loss coefficient in this situation. Other researchers have also questioned the suitability of this basic formula when comparing open channel flows for $90^{\circ}$ bends $[45,49]$.

As the vertical sections within the sump have a fixed cross-sectional area, any increase in the upstream flow in the channel is matched by a rise in the velocity in the sump to ensure continuity is maintained. So as the depth rises in the channel, increasing the discharge, there is a rise in the velocity in the sump leading to more energy dissipation.

If the dimensionless head loss is used instead of head loss then there is a linear correlation between velocity head and the dimensionless head loss (Figure 14). This means the equation for the calculation of head loss (Equation 5) can be modified as follows:

$h_{L}=K_{d} \frac{d v^{2}}{2 g}$

(Equation 10)

where $d$ is the depth $(m)$ and $K_{d}$ is the dimensional minor head loss coefficient $\left(\mathrm{m}^{-1}\right)$. The reduction in the coefficient as the radius of curvature increases is a result of lower head loss, as a consequence of reduced energy dissipation in turbulence created by the sharp corners.

Using the values from Figure 14 and the new minor head loss equation, Equation 10, the head loss can be calculated for any velocity for the geometries modelled, and for any geometry not modelled the coefficient value could be interpolated and the head loss then calculated.

\subsection{Impact of research}

The impact of the power savings which can be made from changing the design of the carbonation sump is considerable. According to literature data, the sump can account for up to $19 \%$ of the total energy required for the cultivation process in a $1000 \mathrm{~m}^{2}$ raceway [2,33]. It may be possible to reduce this by as much as $50 \%$ by altering the geometry of the sump, leading to savings in terms of electrical energy needed for the process and a higher net gain in energy from the biofuel produced.

Apart from direct savings in the energy required for cultivation, the size of the raceways can be increased by almost a fifth. This is a result of the smaller head loss occurring in the raceway, and potentially allows reductions in capital costs associated with the raceway construction and with other economies of scale.

The best case scenarios were found when flow deflectors were used in the bottom of the sump. This also led to smaller dead zones in the riser channels, which would provide a greater volume for contact of the fluid with the carbonated gas, thereby promoting greater gas exchange. This could possibly allow a reduction in the size of the sump, thus reducing the energy loss, while maintaining the same gas transfer potential.

\section{$5 \quad$ Conclusions}

An understanding of the hydrodynamic performance of raceways is very important both to maximise the potential growth of algae and to minimise the energy costs associated with this. Computational Fluid Dynamics has been used to analyse multiple sump geometries and flow conditions with the emphasis on reducing energy costs and areas of stagnant water. 
As the inlet velocity was increased the depth of water upstream also increased. This was attributed to the backwater effect which was greater at higher discharges. As a result of the increased depth the standard formula for calculation of the minor head loss was not applicable and the depth of the water upstream must be used in the calculation.

If the sump barrier length is reduced so that the top of the barrier is at the same height as the bottom of the channel power requirements associated with flow through the sump can be reduced by $94 \%$, equal to those when the sump barrier was removed completely. This gave the greatest saving in energy consumption; however the loss of circulation of the fluid around the sump would result in less effective carbonation and de-oxygenation. The greatest savings with a baffle in place could be achieved with the $0.1 \mathrm{~m}$ radius sump configuration and the use of one deflector. This set-up reduced the power requirements by $73 \%$ compared to the basic configuration.

\section{$6 \quad$ Future perspective}

The future of the production of algae as a source of biofuels requires there to be a very large net gain of energy. Carbonation sumps may not be the most optimal way of achieving this and developing innovative ways of carbonating and deoxygenating the culture medium will most likely occur in the coming years.

\section{Acknowledgements}

Thanks are due to Jose-Luis Mendoza Martin for advice and validating data for experimental raceways and Dr Costantino Manes for help with the numerical modelling. 


\section{Executive summary}

\section{Methodology}

- Computational fluid dynamics simulations using the volume of fluid model were set up to evaluate different carbonation sumps to identify the design with the lowest head loss.

- Different configurations were tested which included:

- Increasing the radius of curvature of the corners of the sump

- Increasing the barrier width.

- The use of flow deflectors in the bottom of the sump.

- Changing the length of the central baffle.

- The simulations were set up as a 2-dimensional model with the use of a symmetrical boundary plane either side of the fluid.

- The head lose across the sump was calculated using Bernoulli's equation.

- Areas of stagnant flow, dead zones, were defined as where the velocity of the fluid dropped below $0.1 \mathrm{~m} \mathrm{~s}^{-1}$.

\section{Results and discussion}

- Depth:

- The depth rose with increasing velocity as a result of the backwater effect.

- Power:

- The power required increased cubically with increasing velocity.

- There was a $40 \%$ reduction in power required when the radius was increased to 0.1 $\mathrm{m}$ due to the elimination of flow separation.

- Increasing the radius further lead to an increase in power required as a result of flow expansion when entering the sump.

- Increasing the barrier was beneficial for small widths of 5-10 cm.

- The use of one flow deflector and a radius of curvature of $0.1 \mathrm{~m}$ led to a power reduction of $77 \%$ compared to the basic configuration.

- Complete removal of the central baffle resulted in a $96 \%$ energy saving but there was no flow around the sump, reducing its gas transfer potential.

- Dead zones:

- Dead zone percentage not affected by the radius of curvature.

- Increasing the barrier width further decreased these areas by up to $52-63 \%$.

- The use of flow deflectors had varying effects depending upon the geometry selected.

- Shear stress:

- The shear stress increased linearly with velocity.

- The main factors modulating the shear stress was the intensity of the localised velocity increases and the boundary surface area in contact with the fluid.

- Minor head loss:

- The minor head loss calculation must include the depth as this affects the fluid velocity in the sump.

Impact and Conclusion

- Increasing the radius to $0.1 \mathrm{~m}$ and the implantation of one vane was the best case and could reduce the power requirement by $77 \%$ compared to the basic configuration.

- There are direct energy savings of new design and the size of the raceway could also be increase by a fifth, leading to savings from economies of scale.

\section{Acknowledgements}

Thanks are due to Jose-Luis Mendoza Martin for advice and validating data for experimental raceways and Dr Costantino Manes for help with the numerical modelling. 


\section{References}

1. Chisti Y. Biodiesel from microalgae beats bioethanol. Trends in Biotechnology, 26(3), 126-131 (2008).

2. Stephenson AL, Kazamia E, Dennis JS, Howe CJ, Scott SA, Smith AG. Life-cycle assessment of potential algal biodiesel production in the United Kingdom: a comparison of raceways and air-lift tubular bioreactors. Energy \& Fuels, 24(7), 4062-4077 (2010).

3. Lundquist TJ, Woertz IC, Quinn N, Benemann JR. A realistic technology and engineering assessment of algae biofuel production. Energy Biosciences Institute, 1-178 (2010).

4. Oswald WJ, Golueke CG. Large scale production of microalgae. In: Single Cell Protein. Mateles, RI, Tannenbaum, SR (Eds.) (M.I.T. Press, Cambridge, 1968) 271-305.

5. Jiménez C, Cossı BR, Xavier Niell F. Relationship between physicochemical variables and productivity in open ponds for the production of Spirulina: a predictive model of algal yield. Aquaculture, 221(1-4), 331-345 (2003).

6. James SC, Boriah V. Modeling algae growth in an open-channel raceway. Journal of computational biology : a journal of computational molecular cell biology, 17(7), 895-906 (2010).

7. Mendoza JL, Granados MR, de Godos I et al. Fluid-dynamic characterization of real-scale raceway reactors for microalgae production. Biomass and Bioenergy, 54, 267-275 (2013).

8. Brennan L, Owende P. Biofuels from microalgae-A review of technologies for production, processing, and extractions of biofuels and co-products. Renewable and Sustainable Energy Reviews, 14(2), 557-577 (2010).

9. Sompech K, Chisti $Y$, Srinophakun T. Design of raceway ponds for producing microalgae. Biofuels, 3(4), 387-397 (2012).

10. Ben-Amotz A. Large Scale open Algal Ponds. (The National Institute of Oceanography, Israel, 2008)

11. Craggs R. Advanced integrated wastewater ponds. In: Pond Treatment Technology, IWA Scientific and Technical Report Series, IWA. Shilton, A (Ed.) (London, UK, 2005) 282-310.

12. Weissman JC, Goebel RP, Benemann JR. Photobioreactor design: mixing, carbon utilization, and oxygen accumulation. Biotechnology and bioengineering, 31(4), 336-344 (1988).

13. Dodd J. Elements of pond design and construction. In: Handbook of microalgal mass culture. Richmond, A (Ed.) (CRC Press, Boca Raton, Florida, 1986) 265-283.

14. Sobczuk TM, Camacho FG, Grima EM, Chisti Y. Effects of agitation on the microalgae Phaeodactylum tricornutum and Porphyridium cruentum. Bioprocess Biosyst Eng, 28(4), 243250 (2006).

15. Hondzo M, Wüest A. Do microscopic organisms feel turbulent flows? Environmental Science \& Technology, 43(3), 764-768 (2008).

16. Thomas W, Gibson C. Effects of small-scale turbulence on microalgae. Journal of Applied Phycology, 2(1), 71-77 (1990).

17. Hsueh HT, Chu H, Yu ST. A batch study on the bio-fixation of carbon dioxide in the absorbed solution from a chemical wet scrubber by hot spring and marine algae. Chemosphere, 66(5), 878-886 (2007).

18. Vunjak-Novakovic G, Kim Y, Wu X, Berzin I, Merchuk JC. Air-Lift Bioreactors for Algal Growth on Flue Gas: Mathematical Modeling and Pilot-Plant Studies. Industrial \& Engineering Chemistry Research, 44(16), 6154-6163 (2005).

19. Kadam KL. Environmental implications of power generation via coal-microalgae cofiring. Energy, 27(10), 905-922 (2002).

20. de Godos I, Mendoza JL, Acién FG et al. Evaluation of carbon dioxide mass transfer in raceway reactors for microalgae culture using flue gases. Bioresource Technology, 153, 307314 (2013).

21. Ketheesan B, Nirmalakhandan N. Feasibility of microalgal cultivation in a pilot-scale airliftdriven raceway reactor. Bioresource Technology, 108, 196-202 (2012). 
22. Kao C-Y, Chen T-Y, Chang Y-B et al. Utilization of carbon dioxide in industrial flue gases for the cultivation of microalga Chlorella sp. Bioresource Technology, 166, 485-493 (2014).

23. Gouveia L. Microalgae as a Feedstock for Biofuels (Springer, 2011).

24. McGinn P, Dickinson K, Bhatti S, Frigon J-C, Guiot S, O'Leary SB. Integration of microalgae cultivation with industrial waste remediation for biofuel and bioenergy production: opportunities and limitations. Photosynth Res, 109(1-3), 231-247 (2011).

25. Berg-Nilsen J. Production of Micro algae based products (Nordic Innovation Centre, Oslo, 2006).

26. Weissman JC, Goebel RP. Design and analysis of microalgal open pond systems for the purpose of producing fuels: A subcontract report (Midwest Research Institute, Golden, Colorado (USA), 1987).

27. Azov Y, Shelef G, Moraine R. Carbon limitation of biomass production in high - rate oxidation ponds. Biotechnology and bioengineering, 24(3), 579-594 (1982).

28. Coutteau P. Manual on the production and use of live food for aquaculture (eds. Lavens, P, Sorgeloos, P) (Food and Agriculture Organization of the United Nations, Rome, 1996).

29. Molina E, Fernández J, Acién FG, Chisti Y. Tubular photobioreactor design for algal cultures. Journal of biotechnology, 92(2), 113-131 (2001).

30. Mendoza JL, Granados MR, de Godos I et al. Oxygen transfer and evolution in microalgal culture in open raceways. Bioresource Technology, 137, 188-195 (2013).

31. Craggs R, Sutherland D, Campbell H. Hectare-scale demonstration of high rate algal ponds for enhanced wastewater treatment and biofuel production. Journal of Applied Phycology, 24(3), 329-337 (2012).

32. Heubeck S, Craggs R, Shilton A. Influence of CO 2 scrubbing from biogas on the treatment performance of a high rate algal pond. Water Science \& Technology, 55(11), 193-200 (2007).

33. Weissman JC, Tillet DM, Goebel RP. Design and Operation of an Outdoor Microalgae Test Facility (Midwest Research Institue, Golden, Colorado, 1989).

34. Liffman K, Paterson DA, Liovic P, Bandopadhayay P. Comparing the energy efficiency of different high rate algal raceway pond designs using computational fluid dynamics. Chemical Engineering Research and Design, 91(2), 221-226 (2012).

35. Hadiyanto H, Elmore S, Van Gerven T, Stankiewicz A. Hydrodynamic evaluations in high rate algae pond (HRAP) design. Chemical Engineering Journal, 217(0), 231-239 (2013).

36. Prussi $M$, Buffi $M$, Casini $D$ et al. Experimental and numerical investigations of mixing in raceway ponds for algae cultivation. Biomass and Bioenergy, 67, 390-400 (2014).

37. $\mathrm{Xu} \mathrm{B}, \mathrm{Li} \mathrm{P}, \mathrm{Waller} \mathrm{P}$. Study of the flow mixing in a novel ARID raceway for algae production. Renewable Energy, 62, 249-257 (2014).

38. Hreiz R, Sialve B, Morchain J, Escudié R, Steyer J-P, Guiraud P. Experimental and numerical investigation of hydrodynamics in raceway reactors used for algaculture. Chemical Engineering Journal, 250, 230-239 (2014).

39. Ramamurthy A, Han S, Biron P. Three-dimensional simulation parameters for $90^{\circ}$ open channel bend flows. Journal of Computing in Civil Engineering, 27(3), 282-291 (2012).

40. Han S, Ramamurthy A, Biron PM. Characteristics of flow around open channel 90 bends with vanes. Journal of Irrigation and Drainage Engineering, 137(10), 668-676 (2011).

41. Naji-Abhari M, Ghodsian M, Vaghefi M, Panahpur N. Experimental and numerical simulation of flow in a $90^{\circ}$ bend. Flow Measurement and Instrumentation, 21(3), 292-298 (2010).

42. lacovides $\mathrm{H}$, Launder BE, Loizou PA. Numerical computation of turbulent flow through a square-sectioned $90^{\circ}$ bend. International Journal of Heat and Fluid Flow, 8(4), 320-325 (1987).

43. Ansys C. Release 14.5. CFX-Solver modeling guide (Ansys, Canonsburg, 2012).

44. Ansys Inc. Ansys Fluent 12.0 User's guide (2009).

45. Malone TR, Parr AD. Bend Losses in Rectangular Culverts (Kansas Department of Transportation, Kansas, 2008). 
46. Jovein EB, Ghaneeizad SM, Akhtari AA. Experimental Study on Flow Structure in Strongly Curved Open Channel 90-degree Bends. In: Proceedings of the International symposium on water management and hydraulic engineering, Ohrid, Macedonia. (2009)

47. Attia M. Energy Losses And Turbulence Characteristics Through Hydraulic Structures Using Laser Doppler Velocimetry (LDV). International Journal of Modern Engineering Research (IJMER), 3(6), 3305-3319 (2013).

48. Ali $\mathrm{H}$, Cheema T, Park C. Effect of Paddle-Wheel Pulsating Velocity on the Hydrodynamic Performance of High-Rate Algal Ponds. Journal of Energy Engineering, 140, 1-12 (2014).

49. Pacheco-Ceballos R. Energy losses and shear stresses in channel bends. Journal of Hydraulic Engineering, 109(6), 881-896 (1983).

\section{Figures}

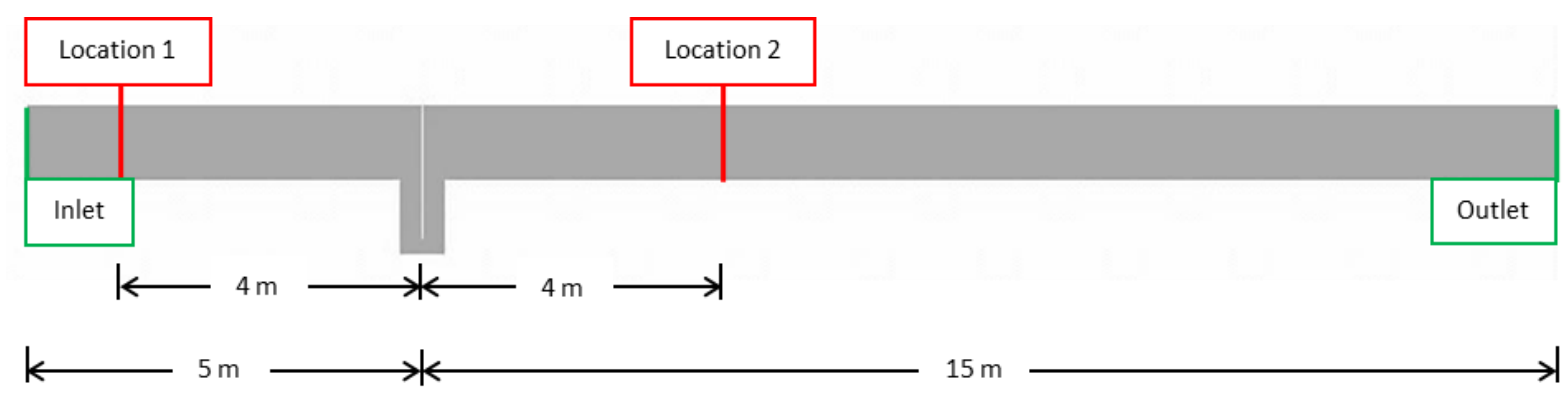

Figure 1. The simulation setup diagram. Location 1 and location 2 are the upstream and downstream data points located $4 \mathrm{~m}$ either side of the baffle.

a)

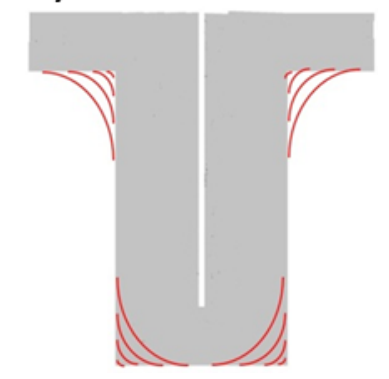

b)

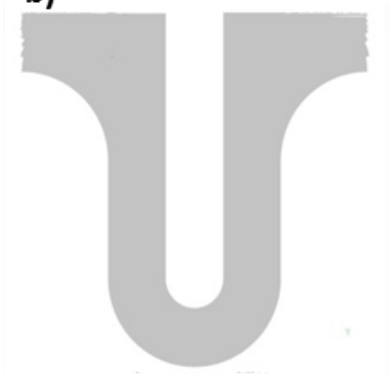

c)

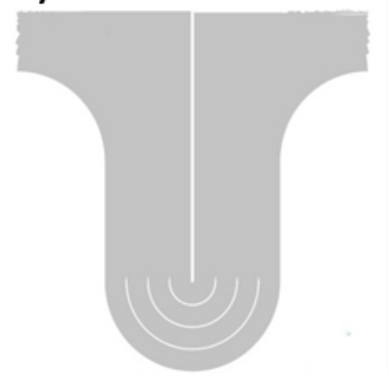

d)

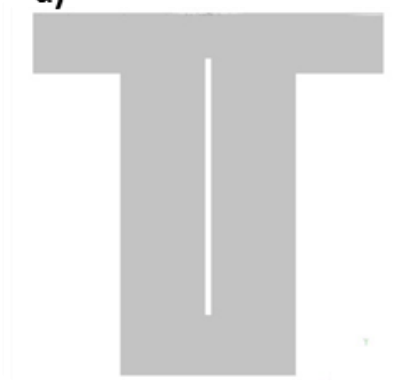

Figure 2. Different sump configurations modelled. a) Basic and rounded sumps: red lines indicate the increase in radius of curvature for the corners. b) Increased barrier thickness. c) Use of flow deflectors. d) Length of the barrier. 

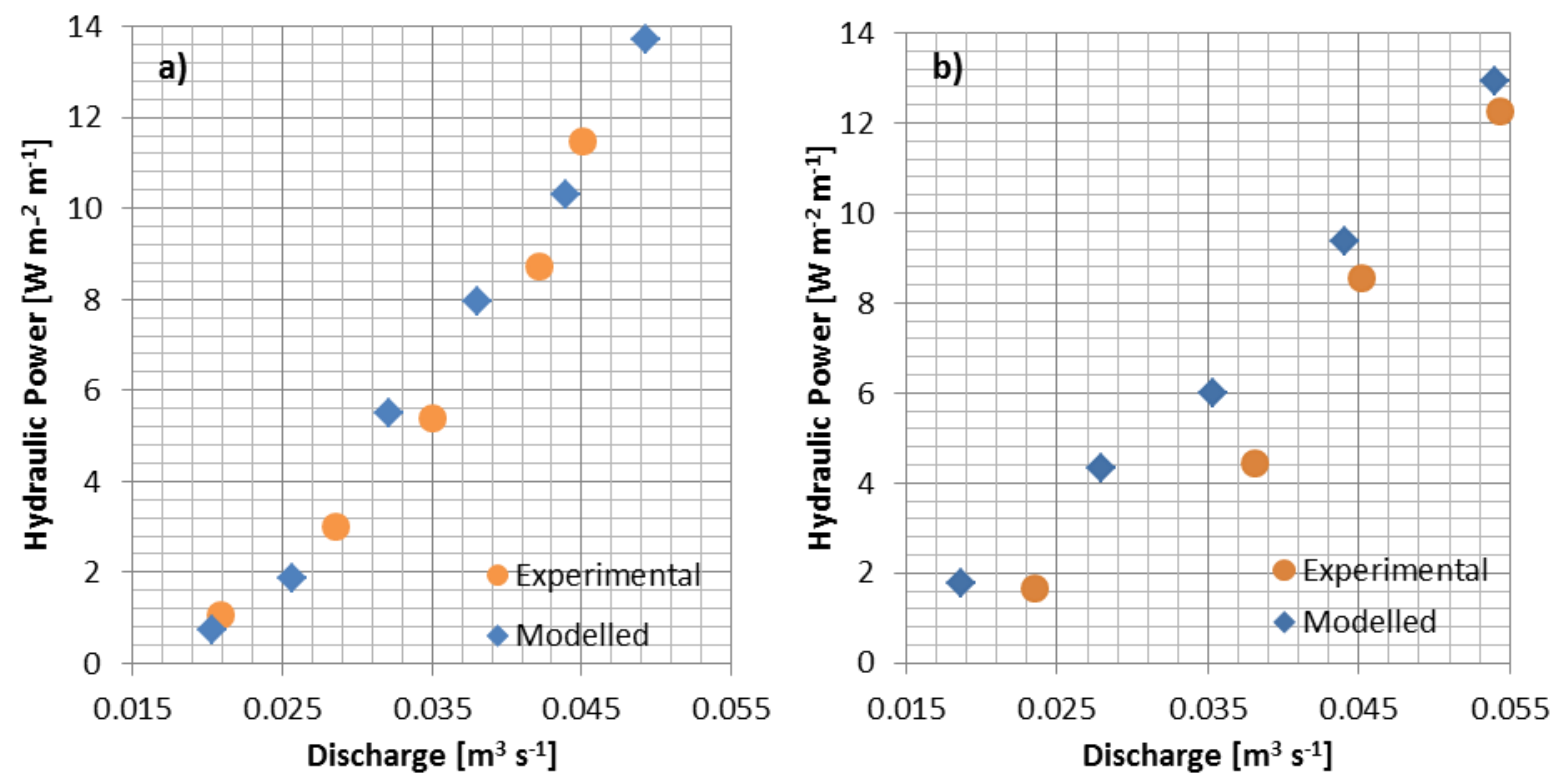

Figure 3. Validation graphs of power consumption per unit of cross-sectional area per unit width for the modelled sump and experimental data. a) Estacion Experimental Las Palmerillas of Fundacion CAJAMAR, b) Weissman et al. [33].

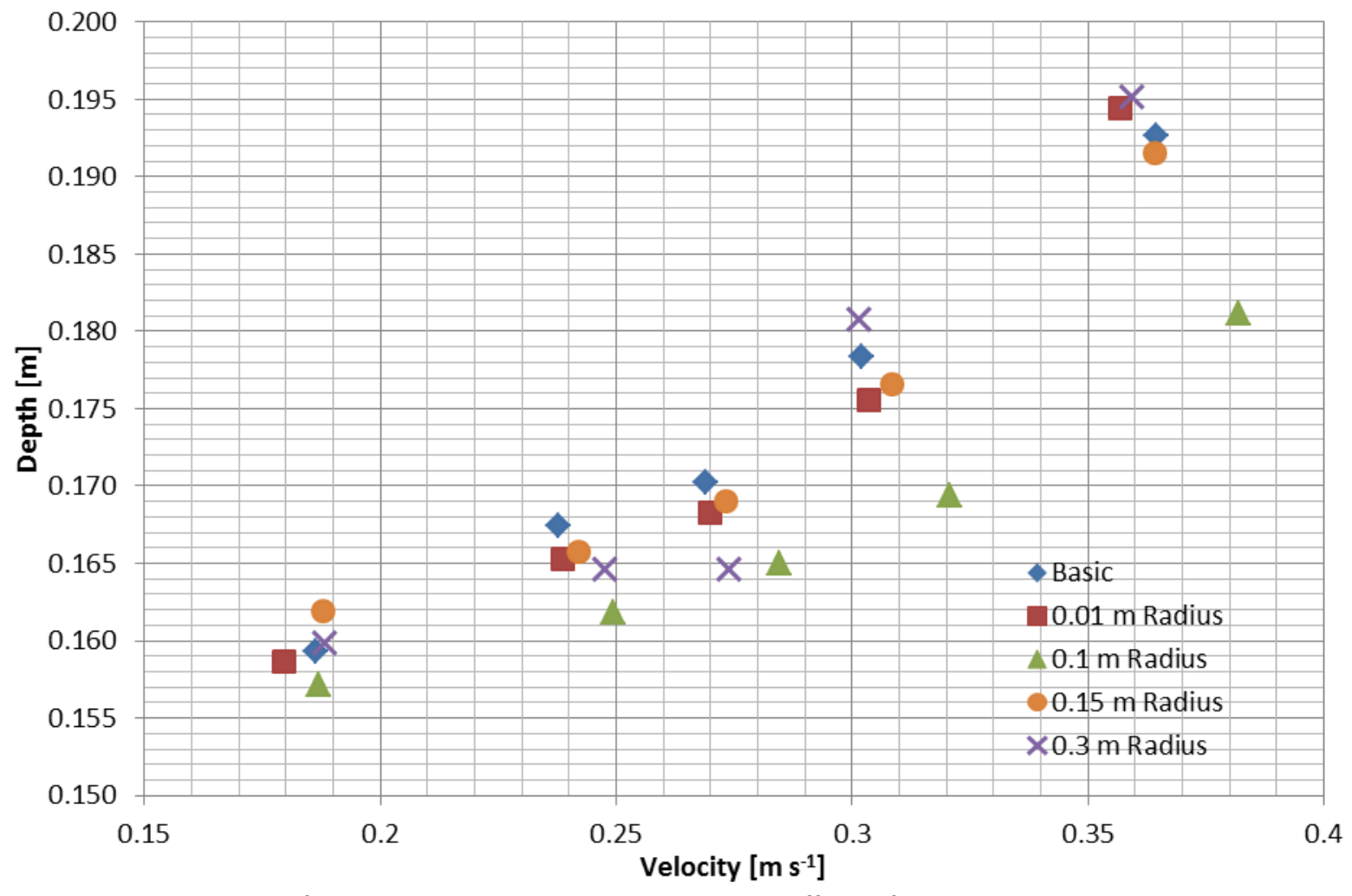

Figure 4. Upstream depth for the basic and rounded sumps tested at different flow velocities 


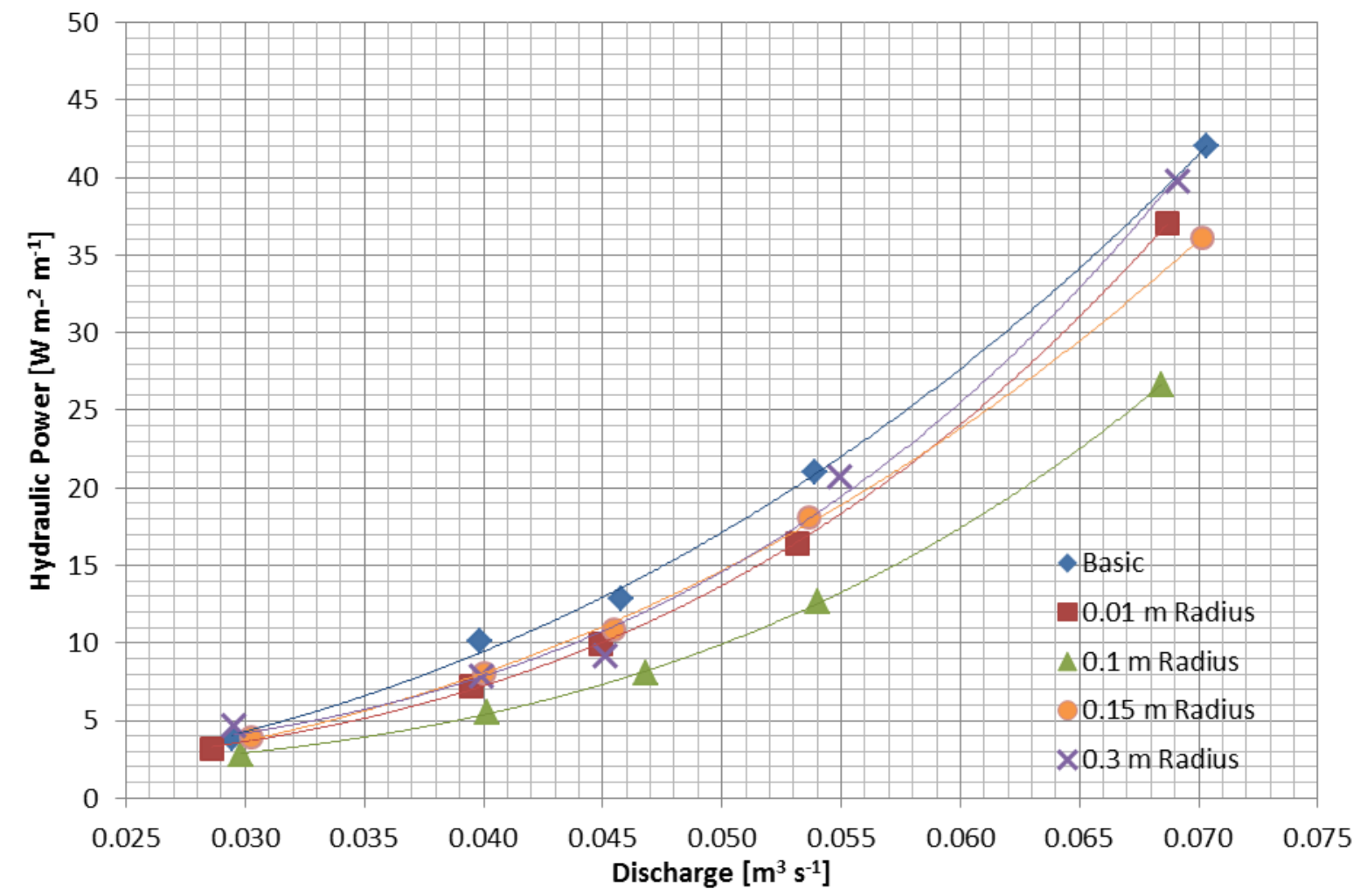

Figure 5. Power consumption per unit area per unit width for the basic and rounded sumps at different discharge flows.

a)

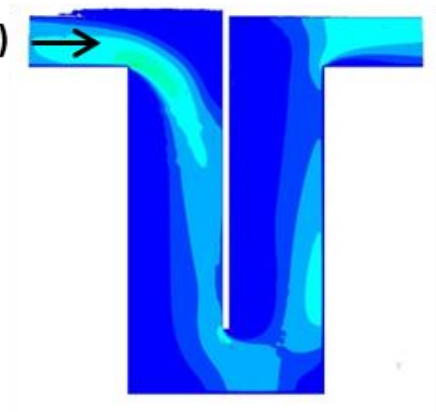

b)

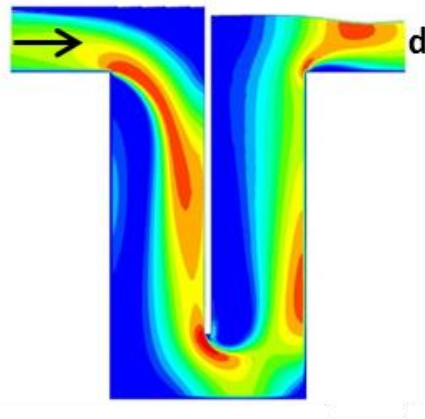

c)

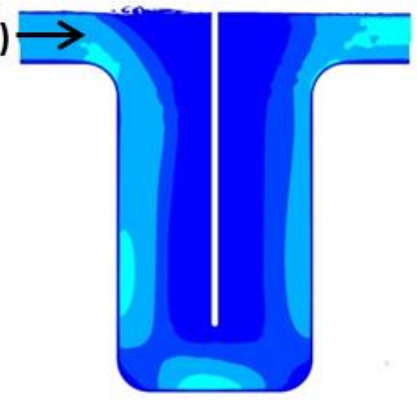

d)

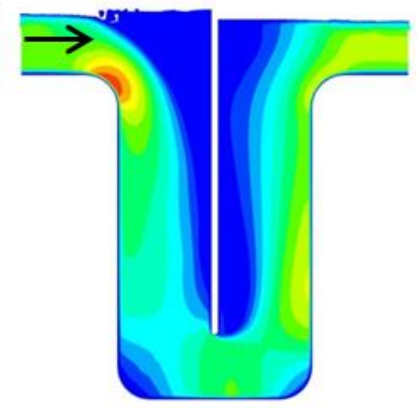

e)

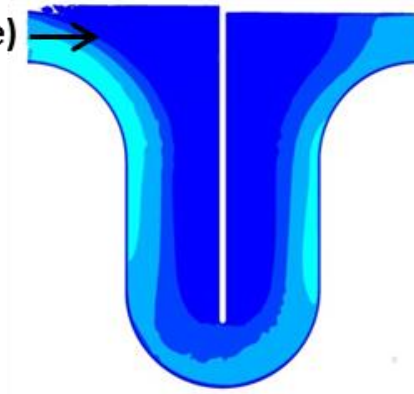

f)

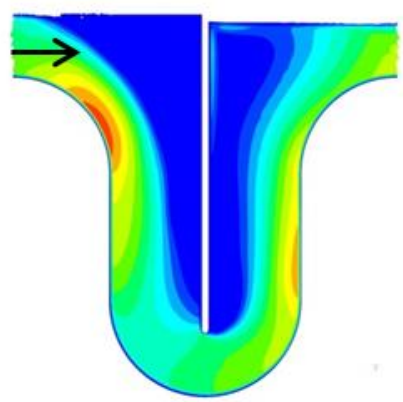

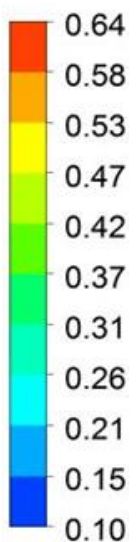

$\left[\mathrm{m} \mathrm{s}^{\wedge}-1\right]$

Figure 6. Flow velocity profiles of different sumps with varying inlet velocities. a) Basic with inlet velocity of $0.15 \mathrm{~ms}^{-1}, \mathrm{~b}$ ) Basic with inlet velocity of $0.35 \mathrm{~ms}^{-1}$, c) Radii of $0.1 \mathrm{~m}$ with inlet velocity of $0.15 \mathrm{~ms}^{-1}$, d) Radii of $0.1 \mathrm{~m}$ with inlet velocity of $0.35 \mathrm{~ms}^{-1}$, e) Radii of $0.3 \mathrm{~m}$ with inlet velocity of $0.15 \mathrm{~ms}^{-1}$, f) Radii of $0.3 \mathrm{~m}$ with inlet velocity of $0.35 \mathrm{~ms}^{-1}$. The black arrows indicate the direction of flow. The dark blue areas indicate where velocity has dropped below $0.1 \mathrm{~ms}^{-1}$. 


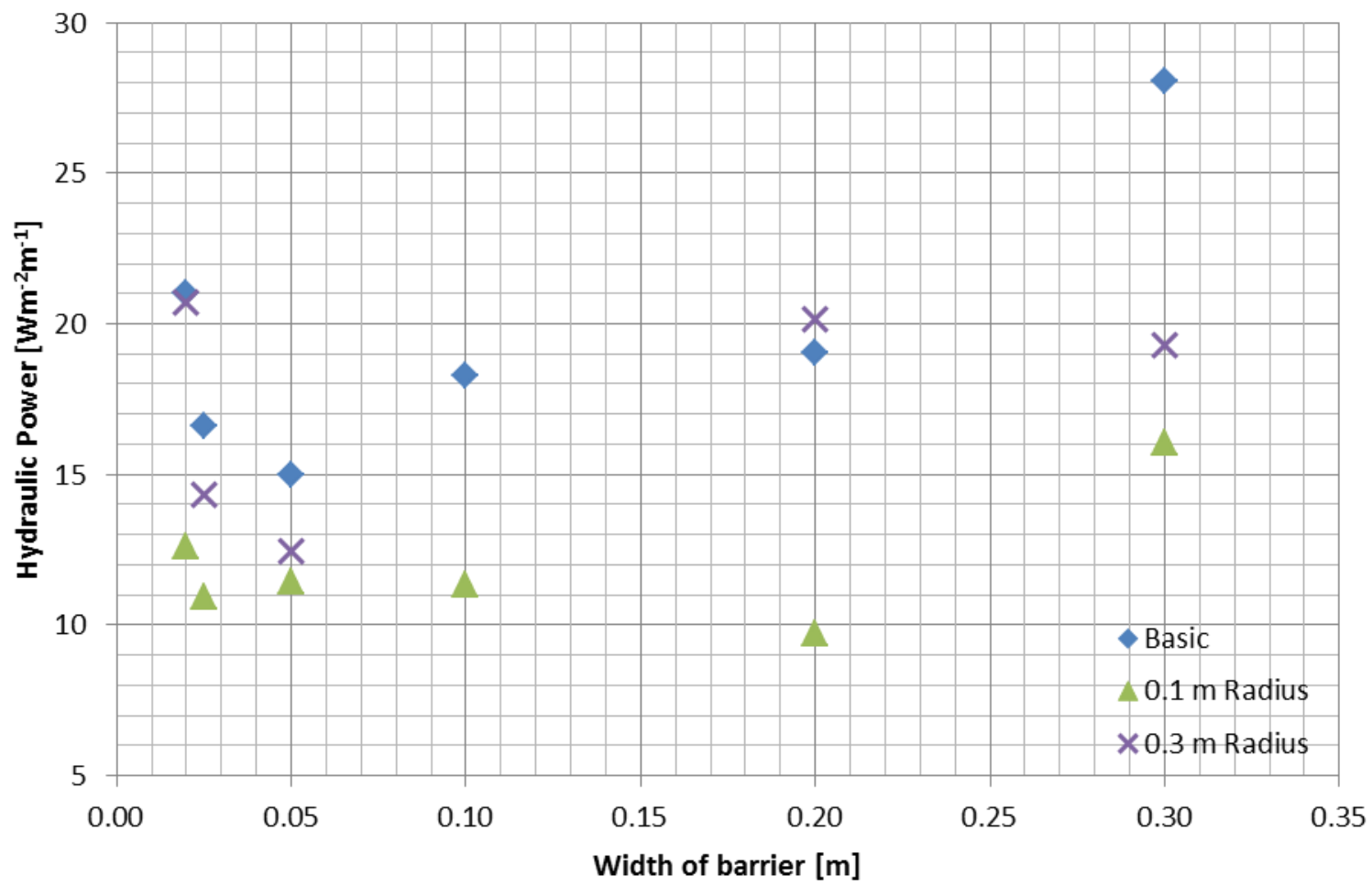

Figure 7. Influence of the barrier width on the power consumption per unit of unit area per unit width.

a)

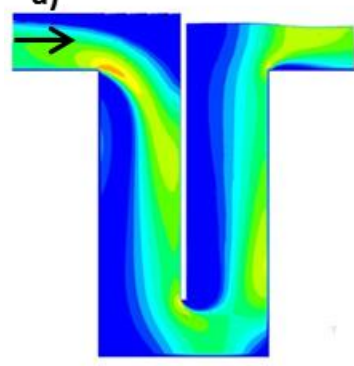

b)

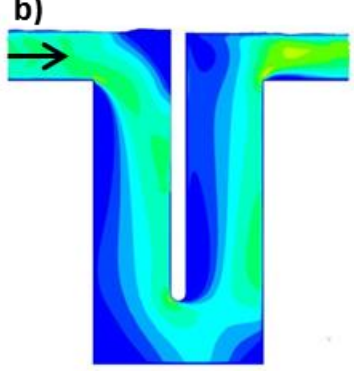

c)

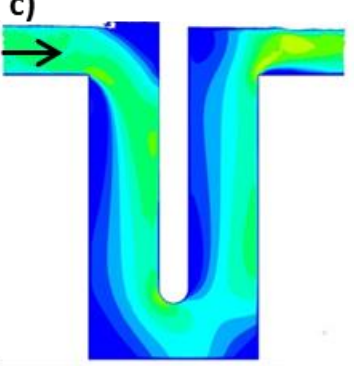

d)

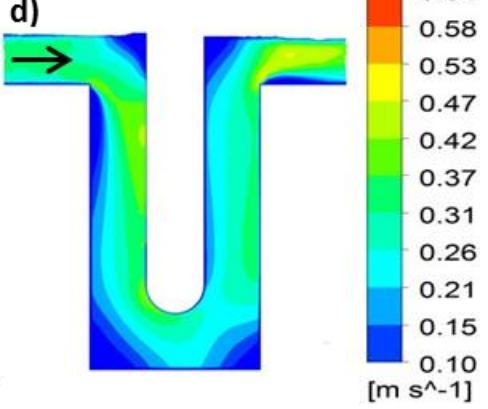

Figure 8. Flow velocity profiles for the basic sump with different barrier widths. a) $0.02 \mathrm{~m}$ barrier, b) $0.05 \mathrm{~m}$ barrier c) $0.1 \mathrm{~m}$ barrier, d) $0.2 \mathrm{~m}$ barrier. All with an inlet velocity set at $0.27 \mathrm{~ms}^{-1}$. The black arrows indicate the direction of flow. The dark blue areas indicate where velocity has dropped below $0.1 \mathrm{~ms}^{-1}$. 


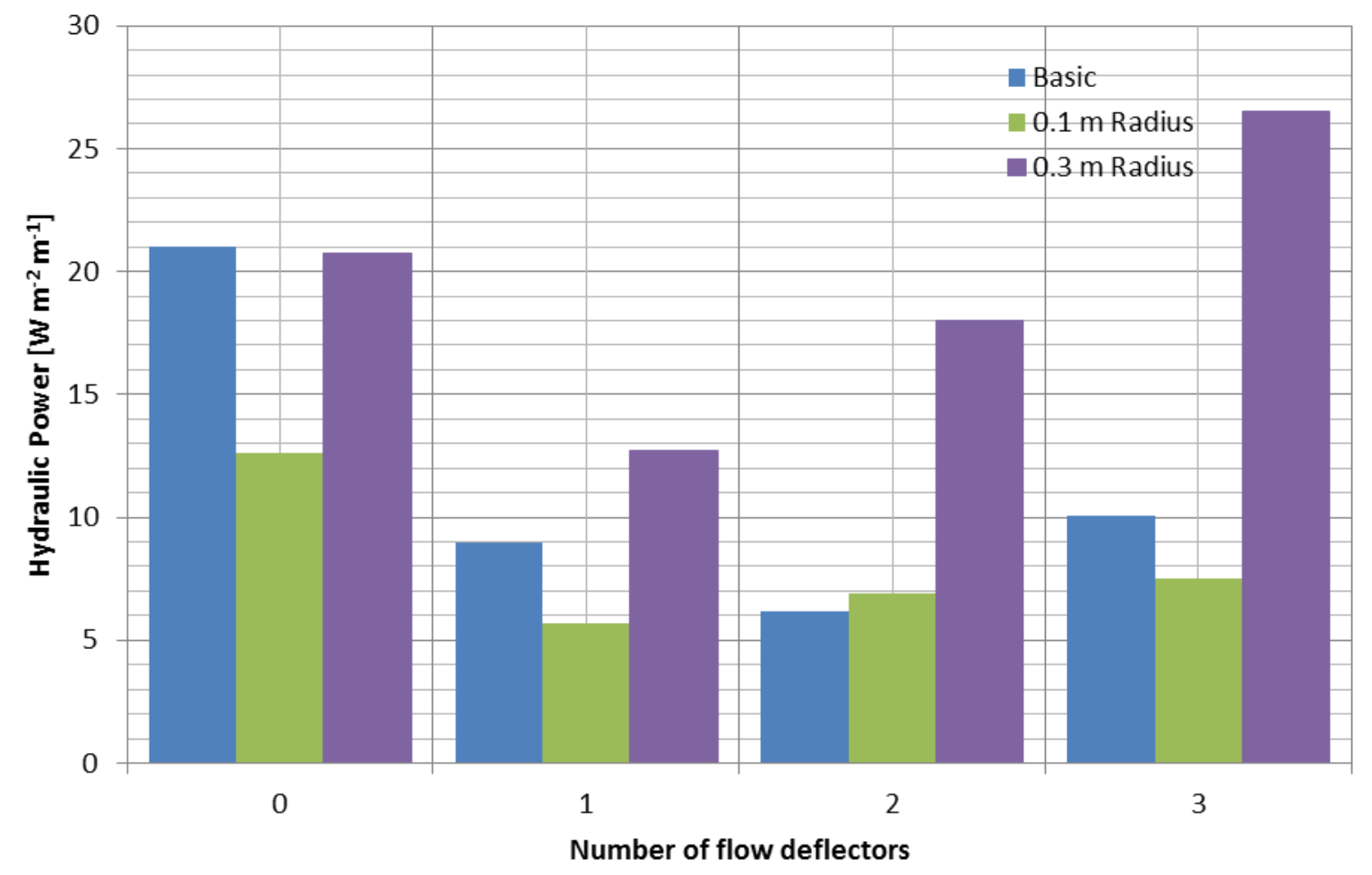

Figure 9. Influence of flow deflectors on the power consumption per unit area per unit width.

a)

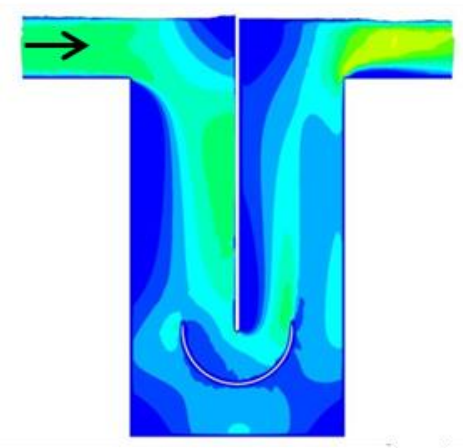

b)

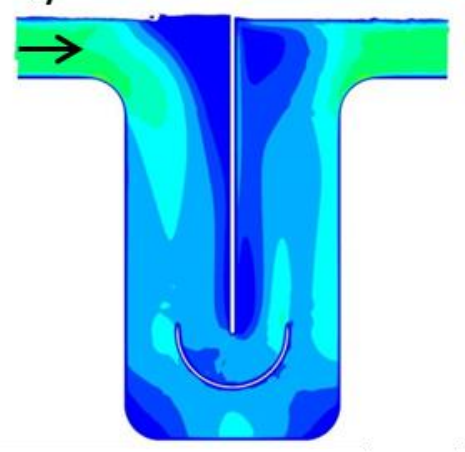

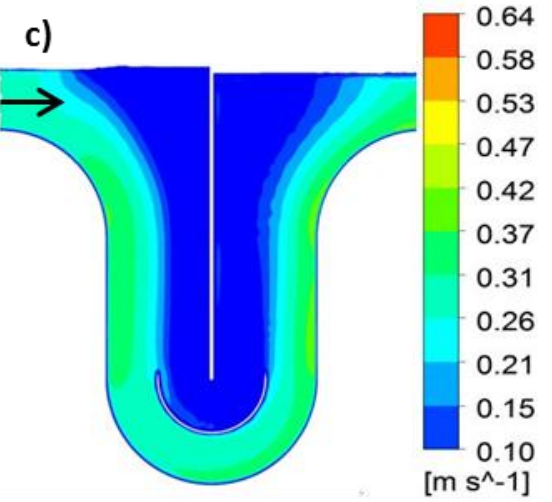

Figure 10. Flow velocity profiles of the sumps with flow deflectors. a) Basic sump, b) $0.1 \mathrm{~m}$ radius sump, c) fully rounded sump with one vane. All with an inlet velocity set at $0.27 \mathrm{~ms}^{-1}$. The black arrows indicate the direction of flow. The dark blue areas indicate where velocity has dropped below $0.1 \mathrm{~ms}^{-1}$. 


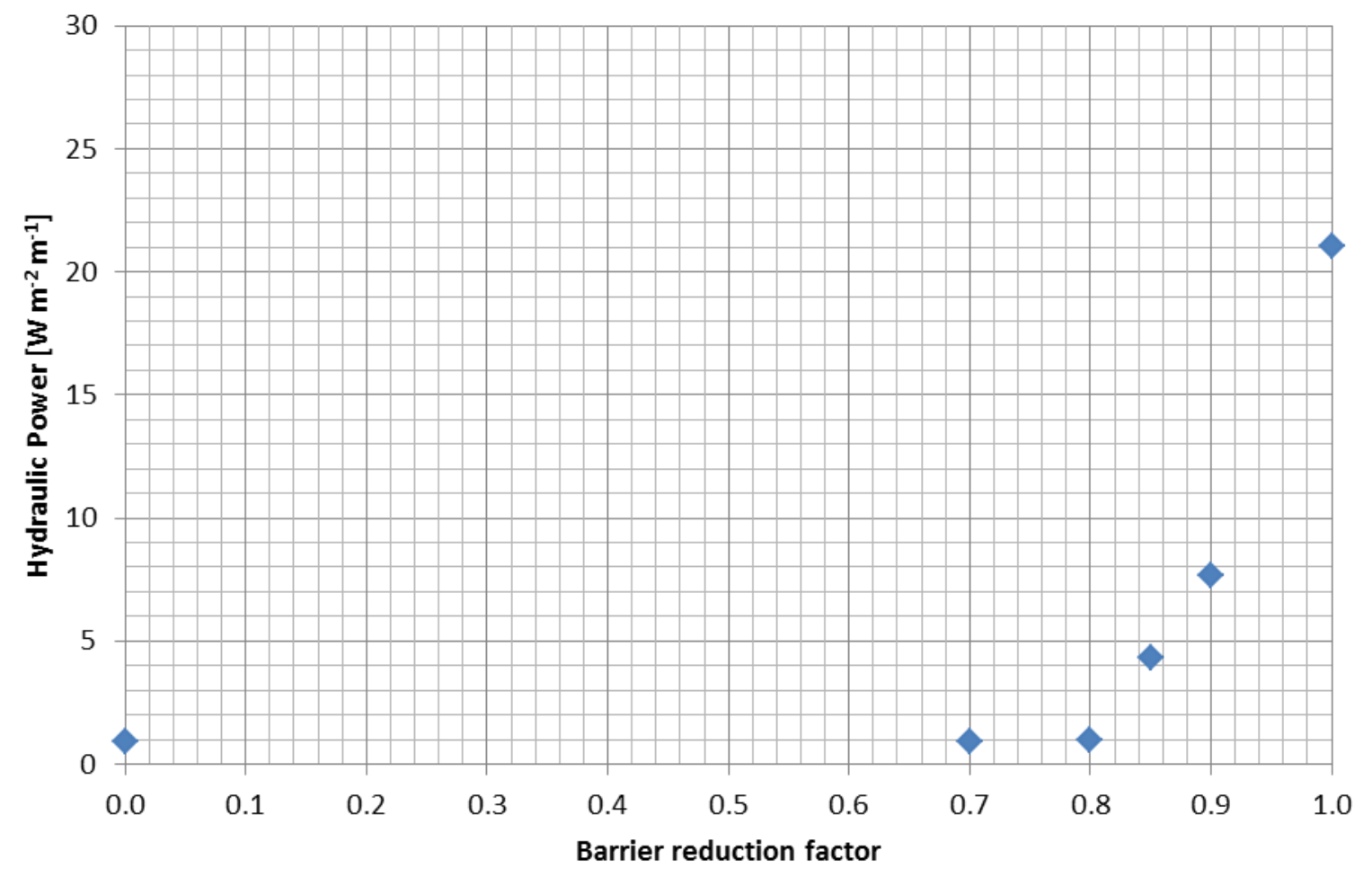

Figure 11. Influence of the length of the barrier on the power requirement for the basic configuration. A reduction factor of 0 is for no barrier and 1 a full length barrier.

a)

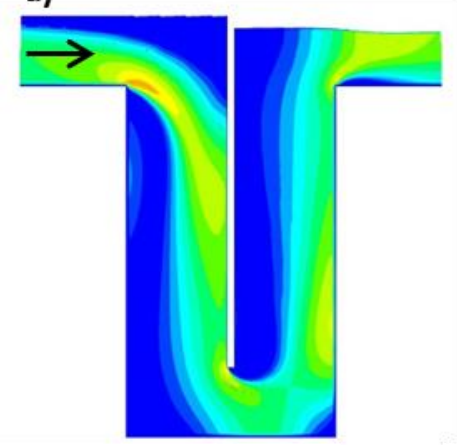

d)

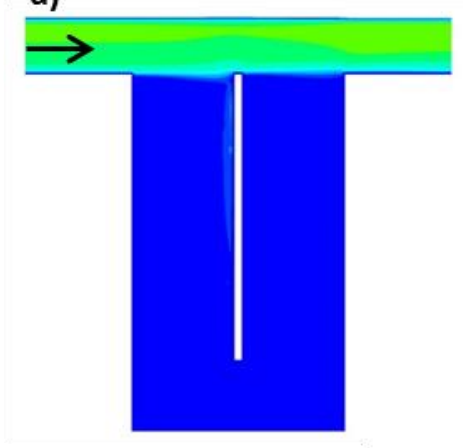

b)

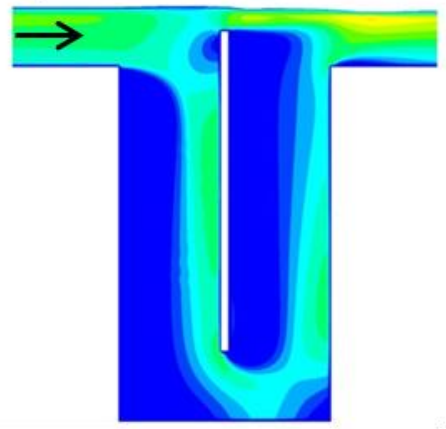

e)

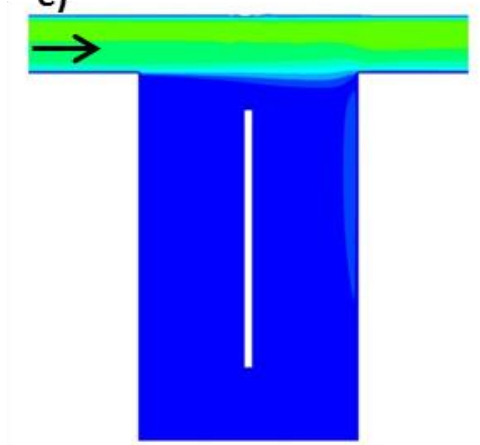

c)

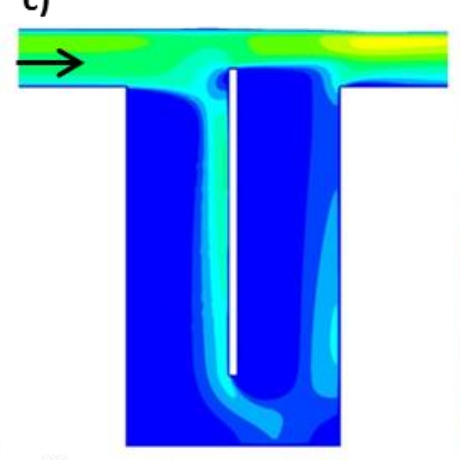

f)

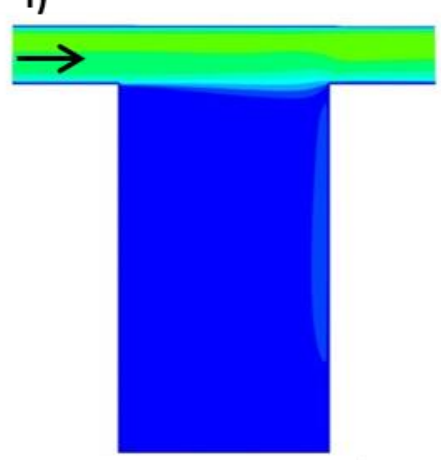

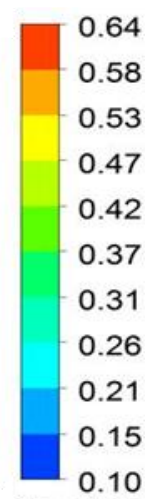

$\left[\mathrm{m} \mathrm{s} \mathrm{s}^{\wedge}-1\right]$

Figure 12. Flow velocity profiles for the standard sump with different barrier lengths. A reduction factor of a) 1, b) $0.9, c)$ 0.85 , d) 0.8 , e) 0.7 , f) 0 . All with an inlet velocity set at $0.27 \mathrm{~ms}^{-1}$. The black arrows indicate the direction of flow. The dark blue areas indicate where velocity has dropped below $0.1 \mathrm{~ms}^{-1}$. 

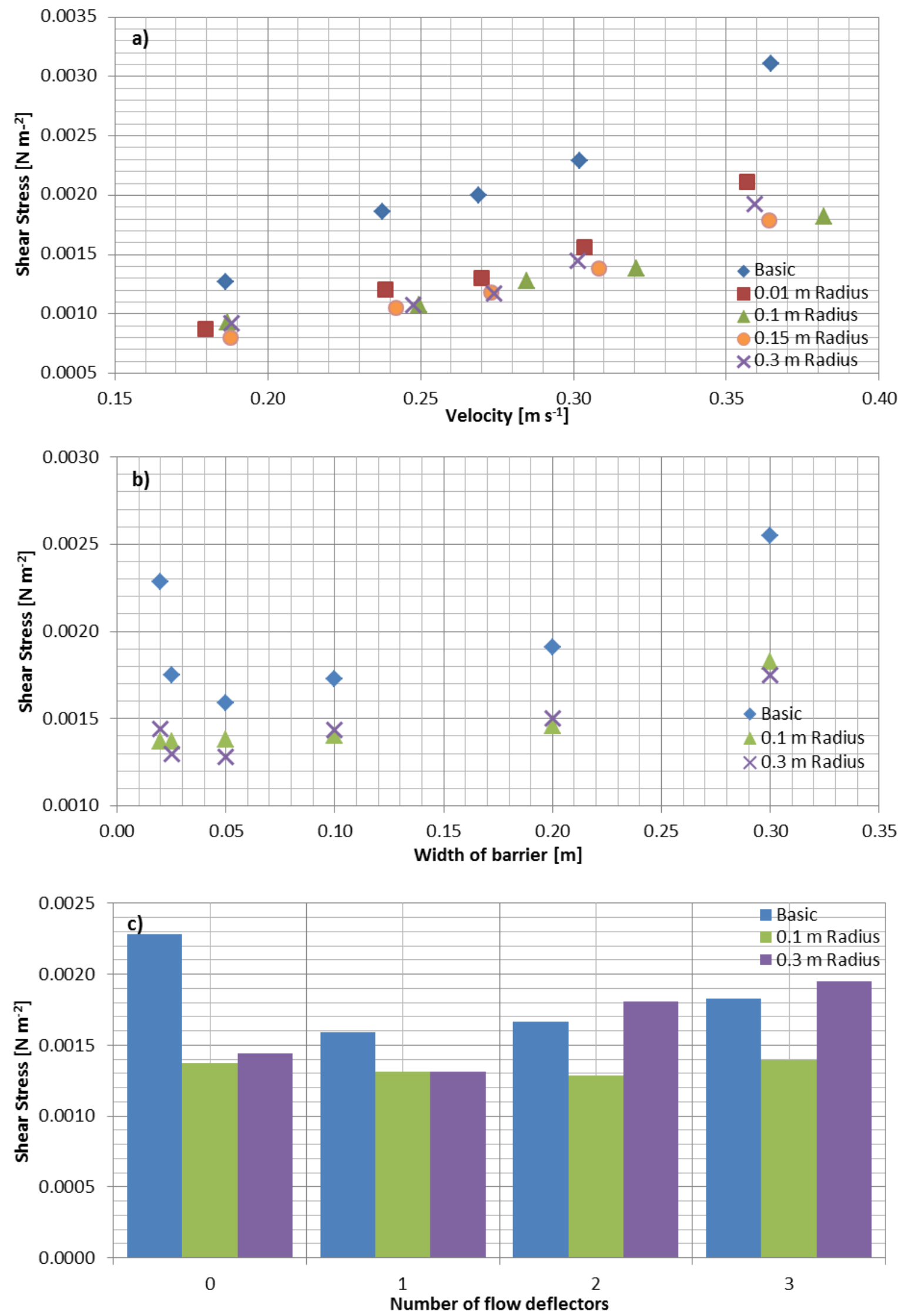

Figure 13. Graphs of the shear stress acting on the fluid. a) Radius of curvature and velocity, b) sump barrier width, c) number of flow deflectors has on it. 


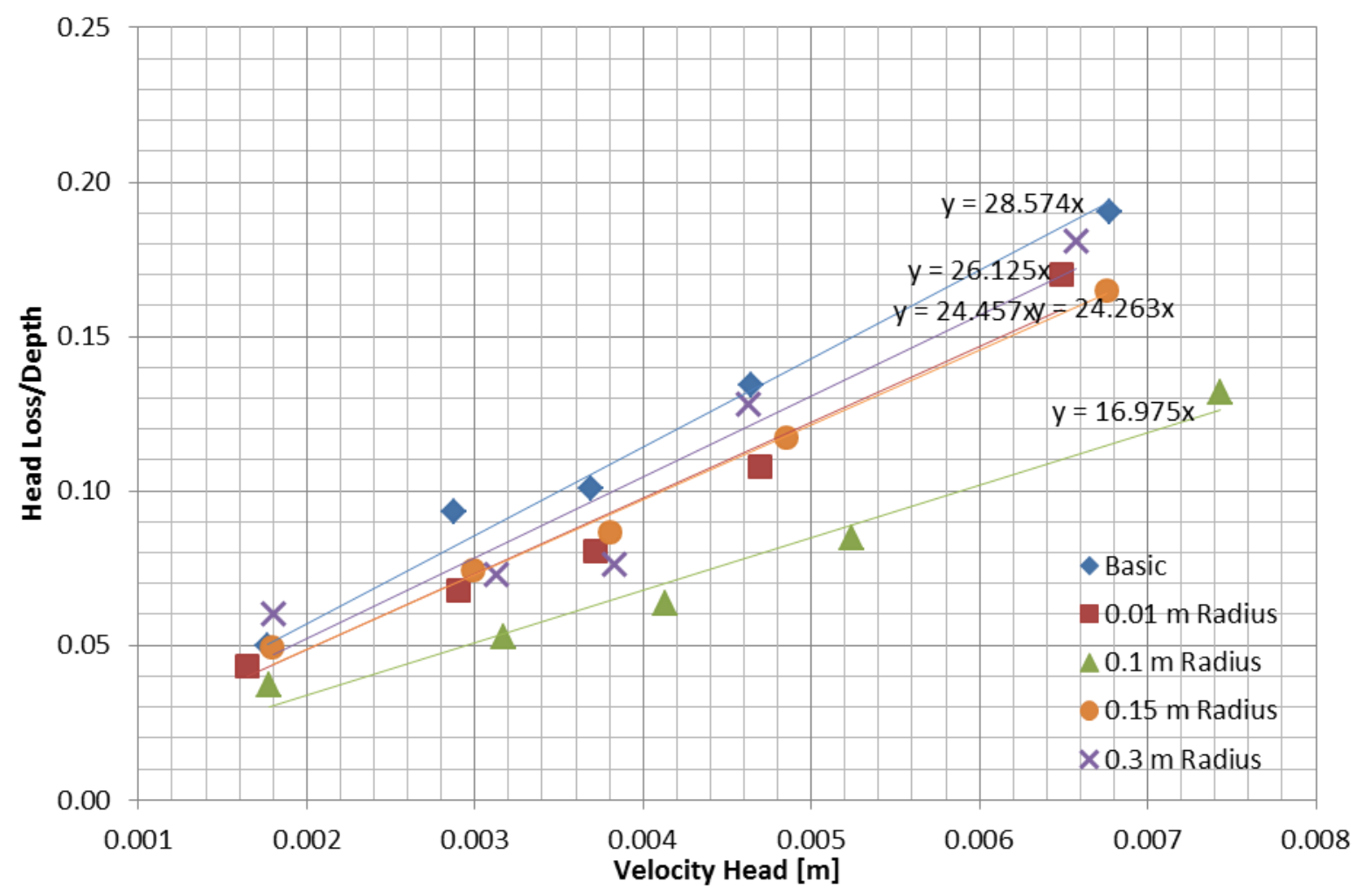

Figure 14. Graph of the velocity head against head loss over depth for the different geometries tested. 